\title{
Is the Clinical Course of Non-Arteritic Ischemic Optic Neuropathy Associated with Oxidative Damage and the Dynamics of the Antioxidant Response?
}

\section{kaya $\mathrm{N}$ engin ( $\boldsymbol{\sim}$ kayanengin@hotmail.com )}

Sağlık University, Ümraniye Education and Research Hospital, Department of Ophthalmology https://orcid.org/0000-0001-6842-1897

\section{Duygu Harmancı Karagülle}

Dokuz Eylül University: Dokuz Eylul Universitesi

\section{Ceren Durmaz Engin}

Dokuz Eylül University: Dokuz Eylul Universitesi

\section{Melis Kant}

Dokuz Eylül University: Dokuz Eylul Universitesi

\section{Aylin Yaman}

Dokuz Eylül University: Dokuz Eylul Universitesi

\section{Merve Akış}

Dokuz Eylül University: Dokuz Eylul Universitesi

\section{Sevda Özel Yıldız}

Istanbul University Istanbul Faculty of Medicine: Istanbul Universitesi Istanbul Tip Fakultesi

\section{Hüray İşlekel}

Dokuz Eylül University: Dokuz Eylul Universitesi

\section{Gül Güner Akdoğan}

İzmir Ekonomi Üniversitesi: Izmir Ekonomi Universitesi

\section{Meltem Söylev Bajin}

Dokuz Eylül University: Dokuz Eylul Universitesi

\section{Research Article}

Keywords: 8-hydroxy-2'-deoxyguanosine, Nonarteritic Anterior Ischemic Optic neuropathy, Stress, Oxidative, Vitamin B12, Vitamin E

Posted Date: January 10th, 2022

DOI: https://doi.org/10.21203/rs.3.rs-1145784/v1 
License: (c) (i) This work is licensed under a Creative Commons Attribution 4.0 International License. Read Full License 


\section{Abstract}

Purpose: Oxidative stress is known to be a decisive factor in the wide etiopathogenesis of optic neuropathy. This study aimed to comprehensively evaluate the interaction of optic neuropathy's clinical course with systemic oxidative damage and antioxidant response dynamics in a large series.

Methods: This case-controlled clinical study included 33 non-arteritic anterior ischemic optic neuropathy patients and 32 healthy individuals. Extensive systemic oxidation profiles were statistically compared between the two groups, and correlations between the clinical and biochemical data in the patient group were analyzed.

Results: Vitamin E and MDA levels were significantly higher in the patient group. Significant correlations were observed in the analyses between clinical findings and oxidative stress parameters. Correlations between vitamin $\mathrm{E}$ and intraocular pressure, between $\mathrm{B}_{12}$ and cup-to-disc ratio, between antioxidant glutathione and SOD enzyme systems, and between uric acid and age were found to be very significant. As significant correlations were found in either clinical and biochemical data or in oxidative stress parameters, correlations between vitamin E and cholesterol, MDA was found to be very significant.

Conclusions: This study not only supplies significant information regarding oxidative damage and antioxidant response in NAION, but also points out the specific interactions of neuromodulators, like vitamin $E$, in intracellular signaling pathways and regulation mechanisms. A better reading of these connections may help improve diagnosis, follow-ups and treatment criteria and strategies.

\section{Introduction}

Non-arteritic anterior ischemic optic neuropathy (NAION) is one of the major causes of vision loss in the elderly and oxidative stress and apoptosis of the retinal ganglion cells play a role in the pathophysiology of the neurological damage [1]. The entire nerve system is rich in lipids and extremely sensitive to oxidative damage [2]. Oxidation degradation products are the sign of oxidative damage in serum and tissue; in lipids, the product is malondialdehyde (MDA) [3]. Molecules, such as uric acid (UA), and vitamins $A, C, E$ remain stable after binding with ionized oxygen, which enables them to exert antioxidant action. Vitamins $A$ and $E$ are liposoluble vitamins. Such compounds, once formed, block the chain reaction by transferring their ions to the systems in which superoxide dismutase (SOD) and glutathione peroxidase are rate-limiting enzymes [4]. The DNA damage due to oxidative stress can be determined specifically from urine 8-hydroxy-2'-deoxyguanosine (8-OHdG) levels $[4,5]$. Elevated serum MDA levels were reported in cataract patients which implies that an ocular pathology may cause signs of oxidative stress in serum [6]. In an observation study, no antioxidant but folate were found to be deficient in prisoners with optic neuropathy [7]. Vitamin $\mathrm{B}_{12}$, on the other hand, is another compound which is of vital importance for neurological damage and required for methylmalonic acid (MMA) metabolism [8]. This study aimed to comprehensively evaluate the interactions between clinical optic neuropathy findings, systemic oxidative damage and antioxidant response dynamics in a large NAION series; in order to obtain 
extensive readings, references and solid information regarding the connection of NAION, and its one-onone, clinical-biochemical parameters, with oxidative damage and the antioxidant response, in a large series of NAION patients.

\section{Methods}

Patients with no known ocular or systemic concomitant disorders, neurological diseases, recent surgeries, or antioxidant and/or corticosteroid usage were selected. The research adhered to the tenets of the Declaration of Helsinki. Approval from the Ethics Committee of Dokuz Eylül University, as well as informed consent from the subjects, were obtained.

33 NAION patients and 32 healthy individuals were included in this study. Biochemical and clinic findings were noted. For oxidative stress analysis, plasma MDA as a lipid oxidation product and urine 8-OHdG as an oxidatively induced DNA damage product were assessed. Along with antioxidants ceruloplasmin (Cp), $\mathrm{UA}$, and vitamins $\mathrm{A}, \mathrm{B}_{12}, \mathrm{C}, \mathrm{E}$ and folate, antioxidant systems SOD, total (tGSH) and reduced glutathione (GSH) were also evaluated. Care was taken to obtain both the samples and clinical data at the same day, and few out-of-range values in certain parameters, -due to errors occurring during and before measurements, were excluded. As extensive systemic oxidation profiles statistically compared the two groups, correlations between clinical and biochemical data in the patient group were also statistically analyzed.

\section{Clinical examinations}

The patients underwent a detailed ophthalmic examination, including mean logarithm of the minimum angle of resolution-best corrected visual acuity (LogMAR-BCVA) and intraocular pressure (IOP) with PASCAL Dynamic Contour Tonometry (Nidek inc., Fremont, CA, USA) measurements. Patients whose IOPs were higher than $21 \mathrm{~mm} / \mathrm{Hg}$ were excluded. Posterior segment analyses with optical coherence tomography (OCT) were taken with a spectral domain OCT (Spectralis; Heidelberg Engineering Ltd, Heidelberg, Germany). Cup-to-disc (c/d) ratio, retinal nerve fiber layer thickness (RNFL) and macular thickness (MT) were also recorded. 30-2 visual field analysis via standard achromatic perimetry (SAP) was conducted with a Humphrey Field Analyzer Model 740i (Carl Zeiss Inc. Dublin, CA, USA), and mean (MD) and pattern standard (PSD) deviations were obtained. Each parameter with basic clinical findings (visual acuity, color vision, age, and gender) were recorded for each patient.

\section{Biochemical analyses}

Serum and fist morning urine samples were collected from patients and healthy subjects. MDA measurement was performed according to the study of Hong et al. [9]. The method is based on the condensation of MDA with thiobarbituric acid (TBA) in the presence of reducing substances. Samples were analyzed using Prominence LC 20 (Shimadzu, Kyoto, Japan) HPLC set equipped with a Sil-20AC autosampler, a LC-20AD pump, and a RF-10Axl fluorescence detector. MDA was detected by fluorescence (excitation $515 \mathrm{~nm}$; emission $553 \mathrm{~nm}$ ). The results were expressed in $\mu \mathrm{mol} / \mathrm{L}$. 
GSH and tGSH activities in serum were determined by HPLC (Shimadzu, Toyo, Japan). This method was based on derivative of GSH with o-Phthalaldehyde (OPA) [10]. The analysis was performed using Prominence LC 20 (Shimadzu, Kyoto, Japan) HPLC set, equipped with a Sil-20AC autosampler, a LC-20AD pump, and a RF-10Axl fluorescence detector. GSH and tGSH were detected by fluorescence (excitation $340 \mathrm{~nm}$, emission $420 \mathrm{~nm}$ ). Results were expressed as $\mu \mathrm{mol} / \mathrm{L}$.

The SOD activity was determined using a RANSOD kit (Randox Labs, Crumlin, UK). The absorbance was measured at $505 \mathrm{~nm}$ on a microplate reader (Bio-Tek Instruments, Inc., VT, USA). Results were expressed as $\mu \mathrm{mol} / \mathrm{mg}$ protein. Vitamin C levels were colorimetrically determined at the Dokuz Eylul University Hospital, via ARLab using the BioTek Synergy HT ELISA Reader (Winooski, USA) with the Ascorbic Acid Assay Kit (Sigma-Aldrich MAK074, Taufkirchen, Germany). The results were expressed in $\mu \mathrm{g} / \mathrm{ml}$.

\section{LC-MS/MS analysis}

a. Plasma MMA analysis: Plasma samples were collected in tubes containing EDTA anticoagulant and were centrifuged immediately at $4^{\circ} \mathrm{C}$ and $2000 \mathrm{xg}$ for ten minutes. The concentration of MMA was measured by LC-MS/MS (Shimadzu Prominence UFLC, Japan and 4000 QTRAP, Applied Biosystems, Germany, respectively), as described previously [11]. Intra- and inter-day MMA precisions were $<3.8 \%$ and $<5.7 \%$, respectively. Results were given in $\mu \mathrm{mol} / \mathrm{L}$. The cut-off value for plasma MMA levels was $0.271 \mu \mathrm{mol} / \mathrm{L}$, which has been frequently used in previous literature [12].

b. 8-OHdG assessment in urine: To evaluate oxidative DNA damage, first morning urine samples were spiked with aliquot of 8-OH-dG- ${ }^{15} \mathrm{~N}_{5}$ as internal standard and LC-MS/MS analyses were performed using a an HPLC system (Shimadzu, Kyoto, Japan) coupled to a triple quadrupole ion-trap mass spectrometer (4000 QTRAP Applied Biosystems, CA, USA) equipped with a TurbolonSpray ${ }^{\mathrm{TM}}$ source, as described previously $[13,14]$. The Analyst Software Version 1.5 (Applied Biosystems) was used for data analyses. Urinary creatinine concentrations were used for normalization of the results. The results were expressed as $\mathrm{nmol} / \mathrm{mmol}$ creatinine.

\section{Statistical analyses}

Statistical analyses were conducted using the IBM Statistical Package for Social Sciences (SPSS) software, version 21.0. The normality of the data was evaluated via the Shapiro-Wilk test. In comparisons between two groups, t-tests and Mann-Whitney $U$ tests were applied for variables showing parametric and non-parametric distributions, respectively. Correlation coefficients were determined with Pearson's and Spearman's correlation tests for variables showing parametric and non-parametric distributions, respectively. For absolute values of correlation coefficients $0-0.19,0.2-0.39,0.40-0.59,0.6-$ 0.79 and 0.8-1 were regarded as very weak, weak, moderate, strong and very strong correlations, respectively. P-values less than 0.05 and 0.01 were considered statistically significant and very significant, respectively.

\section{Results}


No significant differences were found in gender distributions of the patient and control groups. Ages, however, in the control group were significantly higher than the patient group (Table 1). Regarding oxidative stress markers, however, significant differences were observed between two groups (Fig. 1). Compared to the controls, the levels of $\mathrm{GSH}$; vitamins $\mathrm{A}, \mathrm{B}_{12}$ and $\mathrm{E}$; folic acid; MMA; MDA; and 8-OHdG were higher, while tGSH; SOD; vitamin C; $\mathrm{Cp}$; and UA were slightly lower, in the patient group. Statistically, increments in MDA $(t=2,3 p=0,025)$ and Vitamin $E(z=3,648 p<0,001)$ were found to be significant and very significant in the patient group, respectively (Table 2). Comparison of oxidative stress parameters according to gender in patient group is given in Online Resource 1 (ESM_1).

Table 1

Comparison of demographic data between control and patient groups. ${ }^{\dagger} \mathrm{t}$-test, ${ }^{\dagger+}$ Mann-Whitney U Test, * $p<0,05 ;{ }^{* \star} p<0,001$.

\begin{tabular}{|lllll|}
\hline & & Control & Patient & p value \\
\hline Gender $^{\dagger}$ & Female(n)/Male(n) & $23 / 9$ & $17 / 16$ & 0,092 \\
Age $^{t+}$ & Mean \pm Std. Dev. (n) & $64,09 \pm 13,24(32)$ & $57,42 \pm 10,51(33)$ & $0,028^{\star}$ \\
\hline
\end{tabular}


Table 2

Comparison of blood biochemistry and oxidative stress parameters between patient and control groups. Cholesterol (mg/dL), Glucose (mg/dL), tGSH: Total glutathione (mmol/L), GSH: Reduced glutathione,

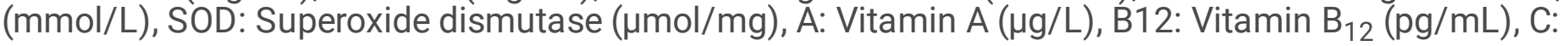

Vitamin C $(n g / \mu L)$, E: Vitamin E $(\mu \mathrm{g} / \mathrm{L})$, Folate $(\mathrm{ng} / \mathrm{mL})$, Cp: Ceruloplasmin $(\mathrm{mg} / \mathrm{dL})$, UA: Uric acid, $(\mu \mathrm{g} / \mathrm{L})$, MMA: Methylmalonic acid ( $\mu \mathrm{mol} / \mathrm{L}), \mathrm{MDA}$ : Malonyl dialdehyde $(\mu \mathrm{mol} / \mathrm{L}), 8-0 \mathrm{HdG}$ : 8-hydroxy-2'deoxyguanosine/Creatinine $(\mathrm{nmol} / \mathrm{mmol}), \mathrm{p}$ : $\mathrm{p}$ value, ${ }^{\dagger} \mathrm{t}$-test, ${ }^{+\dagger}$ Mann-Whitney U Test, $\mathrm{p}$ : $\mathrm{p}$ value, $\mathrm{n}$ : Number of samples, * $p<0,05 ; * \star p<0,001$.

\begin{tabular}{|c|c|c|c|c|}
\hline & & Control & Patient & $\mathbf{p}$ \\
\hline Cholesterol $^{+}$ & Mean \pm Std. Dev. (n) & $209,81 \pm 42,80(31)$ & $206,28 \pm 46,00(32)$ & 0,754 \\
\hline \multirow[t]{2}{*}{ Glucose $^{t \dagger}$} & Mean \pm Std. Dev. (n) & $91,10 \pm 30,77(31)$ & $96,77 \pm 35,69(30)$ & \multirow[t]{2}{*}{0,263} \\
\hline & $\begin{array}{l}\text { Median (25th- 75th } \\
\text { Perc.) }\end{array}$ & $85(74-94)$ & $89,5(77-106)$ & \\
\hline \multirow[t]{2}{*}{$\mathrm{tGSH}^{+\dagger}$} & Mean \pm Std. Dev. (n) & $0,06 \pm 0,04(32)$ & $0,05 \pm 0,017(33)$ & \multirow[t]{2}{*}{0,386} \\
\hline & $\begin{array}{l}\text { Median (25th- 75th } \\
\text { Perc.) }\end{array}$ & $0,051(0,041-0,063)$ & $0,047(0,039-0,060)$ & \\
\hline \multirow[t]{2}{*}{$\mathrm{GSH}^{+\dagger}$} & Mean \pm Std. Dev. (n) & $0,031 \pm 0,015(32)$ & $0,032 \pm 0,013(33)$ & \multirow[t]{2}{*}{0,679} \\
\hline & $\begin{array}{l}\text { Median (25th- 75th } \\
\text { Perc.) }\end{array}$ & $0,03(0,02-0,037)$ & $0,029(0,023-0,04)$ & \\
\hline \multirow[t]{2}{*}{$\mathrm{SOD}^{++}$} & Mean \pm Std. Dev. (n) & $23,01 \pm 15,70(32)$ & $22,39 \pm 10,06(33)$ & \multirow[t]{2}{*}{0,486} \\
\hline & $\begin{array}{l}\text { Median (25th- 75th } \\
\text { Perc.) }\end{array}$ & $20,97(11,46-30,49)$ & $24(13,51-30,27)$ & \\
\hline \multirow[t]{2}{*}{$\mathrm{A}^{\dagger+}$} & Mean \pm Std. Dev. (n) & $929,85 \pm 303,73(31)$ & $1051,18 \pm 259,52(33)$ & \multirow[t]{2}{*}{0,065} \\
\hline & $\begin{array}{l}\text { Median (25th- 75th } \\
\text { Perc.) }\end{array}$ & $\begin{array}{l}882,3(676,4- \\
1174,6)\end{array}$ & $\begin{array}{l}1072,8(925,8- \\
1211,7)\end{array}$ & \\
\hline \multirow[t]{2}{*}{$\mathrm{B} 12^{++}$} & Mean \pm Std. Dev. (n) & $251,16 \pm 169,74(31)$ & $210,93 \pm 85,98(30)$ & \multirow[t]{2}{*}{0,644} \\
\hline & $\begin{array}{l}\text { Median (25th- 75th } \\
\text { Perc.) }\end{array}$ & 215(144-275) & 193(159-265) & \\
\hline \multirow[t]{2}{*}{$\mathrm{C}^{+\dagger}$} & Mean \pm Std. Dev. (n) & $0,075 \pm 0,032(32)$ & $0,074 \pm 0,037(33)$ & \multirow[t]{2}{*}{0,454} \\
\hline & $\begin{array}{l}\text { Median (25th- 75th } \\
\text { Perc.) }\end{array}$ & $0,074(0,057-0,095)$ & $0,067(0,056-0,086)$ & \\
\hline \multirow[t]{2}{*}{$\mathrm{E}^{+\dagger}$} & Mean \pm Std. Dev. (n) & $15,03 \pm 8,07(32)$ & $22,06 \pm 8,54(33)$ & \multirow[t]{2}{*}{$<0,001^{\star \star}$} \\
\hline & $\begin{array}{l}\text { Median (25th- 75th } \\
\text { Perc.) }\end{array}$ & $13,22(11-17,3)$ & $21,6(18,3-28,5)$ & \\
\hline \multirow[t]{2}{*}{ Folate $^{\dagger \dagger}$} & Mean \pm Std. Dev. (n) & $8,17 \pm 3,27(31)$ & $9,46 \pm 5,04(32)$ & \multirow[t]{2}{*}{0,372} \\
\hline & $\begin{array}{l}\text { Median (25th- 75th } \\
\text { Perc.) }\end{array}$ & $7,64(5,5-10,7)$ & $8,85(5,9-10,9)$ & \\
\hline
\end{tabular}




\begin{tabular}{|c|c|c|c|c|}
\hline & & Control & Patient & $\mathbf{p}$ \\
\hline \multirow[t]{2}{*}{$\mathrm{Cp}^{+\dagger}$} & Mean \pm Std. Dev. (n) & $20,27 \pm 3,31(31)$ & $20,13 \pm 4,04(31)$ & \multirow[t]{2}{*}{0,899} \\
\hline & $\begin{array}{l}\text { Median (25th- 75th } \\
\text { Perc.) }\end{array}$ & $19,8(17,5-21,8)$ & $20,2(17-22,4)$ & \\
\hline \multirow[t]{2}{*}{$\mathrm{MMA}^{+\dagger}$} & Mean \pm Std. Dev. (n) & $0,379 \pm 0,496(32)$ & $0,269 \pm 0,223(24)$ & \multirow[t]{2}{*}{0,345} \\
\hline & $\begin{array}{l}\text { Median (25th- 75th } \\
\text { Perc.) }\end{array}$ & $0,202(0,148-0,345)$ & $0,153(0,126-0,408)$ & \\
\hline Uric acid ${ }^{\dagger}$ & Mean \pm Std. Dev. (n) & $5,38 \pm 1,58(31)$ & $5,34 \pm 1,17(32)$ & 0,899 \\
\hline $\mathrm{MDA}^{\dagger}$ & Mean \pm Std. Dev. (n) & $2,57 \pm 0,72(31)$ & $3,04 \pm 0,89(32)$ & $0,025^{\star}$ \\
\hline \multirow[t]{2}{*}{$8-\mathrm{OHdG}^{+\dagger}$} & Mean \pm Std. Dev. (n) & $12,41 \pm 9,09(27)$ & $14,93 \pm 10,36(28)$ & \multirow[t]{2}{*}{0,523} \\
\hline & $\begin{array}{l}\text { Median (25th- 75th } \\
\text { Perc.) }\end{array}$ & $11,17(5,52-16,35)$ & $11,85(5,56-19,72)$ & \\
\hline
\end{tabular}

In the patient group, significant and very significant correlations were observed in statistical analyses performed between clinical findings and oxidative stress parameters, along with correlations between clinical and biochemical data. In the correlation analysis between clinical and biochemical data in the patient group, negative correlations between color vision with age, as well as between RNFL and vision, were statistically very significant. Positive correlation between age and vision and negative correlation between color vision and RNFL were also significant (Table 3). Correlation analysis between clinical and biochemical data showing parametric (ESM_2) and non-parametric (ESM_3) distributions in the patient group is given in Online Resources 2 and 3, respectively.

Table 3

Significant and highly significant correlations between clinical and biochemical data in the patient group. C Vs: Color vision, RNFL: Retinal nerve fiber layer analysis. r: Pearson correlation coefficients, $p: p$ value, $p: p$ value, $n$ : Number of samples, * $p<0,05 ; * * p<0,001$.

\begin{tabular}{|lllllll|}
\hline & & & $\mathbf{r}$ & $\mathbf{p}$ & $\mathbf{n}$ & \\
\hline Age & - & Vision & 0,405 & $0,19 *$ & 32 & $\mathrm{M}$ \\
\hline Age - & CVs & $-0,582$ & $<0,001$ ** & 32 & $\mathrm{~S}$ \\
\hline Vision - & CVs & $-0,633$ & $<0,001$ ** & 32 & S \\
\hline Vision - & RNFL & $-0,601$ & $<0,001$ ** & 32 & S \\
\hline C Vs & - & RNFL & 0,354 & $0,047 *$ & 32 & W \\
\hline
\end{tabular}

Regarding oxidative stress parameters, UA showed very significant and significant positive correlations with age and IOP, respectively. Significant positive and negative correlations were observed between 
cholesterol and MDA, and between glucose and Vitamin A, 8-OHdG, respectively. Whereas a strong and very significant negative correlation was observed between Vitamin $B_{12}$ and $c / d$ ratio, Vitamin $E$ was very significantly and significantly correlated with cholesterol and IOP, respectively. MD showed very significant and significant negative correlations with MMA and Cp, respectively (Table 4). Correlation analysis of oxidative stress parameters with clinical and biochemical data showing parametric (ESM_4) and non-parametric (ESM_5) distributions in the patient group is given in Online Resources 4 and 5, respectively.

Table 4

Significant and highly significant correlations of oxidative stress parameters with clinical and biochemical data in the patient group. c/d: Cup disc ratio, Ch: Cholesterol (mg/dL), Glu: Glucose (mg/dL), tGSH: Total glutathione (mmol/L), GSH: Reduced glutathione, (mmol/L), SOD: Superoxide dismutase $(\mu \mathrm{mol} / \mathrm{mg}), A$ : Vitamin A $(\mu \mathrm{g} / \mathrm{L})$, B12: Vitamin $B_{12}$ $(\mathrm{pg} / \mathrm{mL}), \mathrm{C}:$ Vitamin $\mathrm{C}(\mathrm{ng} / \mu \mathrm{L}), \mathrm{E}:$ Vitamin $\mathrm{E}(\mu \mathrm{g} / \mathrm{L})$, Folate $(\mathrm{ng} / \mathrm{mL}), \mathrm{Cp}$ : Ceruloplasmin $(\mathrm{mg} / \mathrm{dL})$, IOP: Intraocular pressure, UA: Uric acid, $(\mu \mathrm{g} / \mathrm{L}), \mathrm{MMA}$ : Methylmalonic acid $(\mu \mathrm{mol} / \mathrm{L}), \mathrm{MD}$ : Mean deviation, MDA: Malonyl dialdehyde ( $\mu \mathrm{mol} / \mathrm{L}), 8-\mathrm{OHdG}$ : 8-hydroxy2'-deoxyguanosine/Creatinine ( $\mathrm{nmol} / \mathrm{mmol})$, r: Pearson correlation coefficients, ${ }^{\dagger} S$ pearman's rho correlation coefficients, $p$ : $p$ value, $p$ : $p$ value, $n$ : Number of samples, ${ }^{*} p<0,05 ; * \star p<0,01 ; * \star \star p<<0,001$.

\begin{tabular}{|c|c|c|c|c|c|c|}
\hline & & & $r$ & p & $\mathrm{n}$ & \\
\hline Age & - & UA & 0,551 & $0,001^{\star \star}$ & 31 & M \\
\hline MD & - & $\mathrm{Cp}$ & $-0,412$ & $0,015^{\star}$ & 30 & M \\
\hline MD & - & MMA & $-0,569^{\dagger}$ & $0,004^{\star \star}$ & 24 & M \\
\hline $\mathrm{Ch}$ & - & MDA & 0,431 & $0,014^{*}$ & 32 & M \\
\hline $\mathrm{Ch}$ & - & E & 0,52 & $0,002^{\star \star}$ & 32 & M \\
\hline IOP & - & E & $0,459^{\dagger}$ & $0,007 \star \star$ & 32 & M \\
\hline IOP & - & UA & $0,387^{\dagger}$ & $0,029 *$ & 32 & M \\
\hline$c / d$ & - & B12 & $-0,700^{\dagger}$ & $<0,001^{\star \star}$ & 29 & $S$ \\
\hline Glu & - & A & $-0,399^{\dagger}$ & $0,029 *$ & 30 & W \\
\hline Glu & . & 8-OHdG & $-0,467^{\dagger}$ & $0,019 *$ & 25 & M \\
\hline
\end{tabular}

In the correlation analysis between oxidative stress parameters in the patient group, antioxidant glutathione and SOD enzyme systems were found to correlate very significantly. tGSH showed negative and positive significant correlations with both Vitamin $B_{12}$ and MMA, respectively. MMA was also 
significantly correlated with $\mathrm{Cp}$. Correlations between SOD and gluthationes were negative. Whereas correlation of MDA and cholesterol was significant, very significant correlations between Vitamin $\mathrm{E}$ with vitamin $A$ and MDA were the other prominent findings regarding antioxidant response dynamics. Despite statistically significant $p$ values in the corelations between GSH and SOD, glucose and vitamin A, corelation coefficients were below 0.500 which implies a low corelation (Table 5). Correlation analysis between oxidative stress parameters and biochemical data showing parametric (ESM_6) and nonparametric (ESM_7) distributions in the patient group is given in Online Resources 6 and 7, respectively.

Table 5

Significant and highly significant correlations between oxidative stress parameters and biochemical data in the patient group. $\mathrm{Cp}$ : Ceruloplasmine, MMA:

Methylmalonic acid, MDA: Malonyl dialdehyde, tGSH: Total glutathione $(\mathrm{mmol} / \mathrm{L}), \mathrm{GSH}$ : Reduced glutathione, (mmol/L), SOD: Superoxide dismutase $(\mu \mathrm{mol} / \mathrm{mg}), A:$ Vitamin A $(\mu \mathrm{g} / \mathrm{L})$, B12: Vitamin $B_{12}$ $(\mathrm{pg} / \mathrm{mL})$, E: Vitamin $\mathrm{E}(\mu \mathrm{g} / \mathrm{L}), \mathrm{Cp}$ : Ceruloplasmin (mg/dL), MMA: Methylmalonic acid ( $\mu \mathrm{mol} / \mathrm{L}), M D A$ : Malonyl dialdehyde $(\mu \mathrm{mol} / \mathrm{L})$, r: Pearson correlation coefficients, ${ }^{\dagger}$ Spearman's rho correlation coefficients, * $p<0,05 ;{ }^{* *} p<0,01$.

\begin{tabular}{|lllllll|}
\hline & & & $\mathbf{r}$ & $\mathbf{p}$ & $\mathbf{n}$ & \\
\hline tGSH & - & $\mathrm{B} 12$ & $-0,402^{\dagger}$ & $0,028^{*}$ & 30 & $\mathrm{M}$ \\
\hline $\mathrm{tGSH}$ & - & $\mathrm{MMA}$ & $0,417^{\dagger}$ & $0,043^{*}$ & 24 & $\mathrm{M}$ \\
\hline $\mathrm{tGSH}$ & - & $\mathrm{GSH}$ & 0,447 & $0,009^{* *}$ & 33 & $\mathrm{M}$ \\
\hline $\mathrm{tGSH}$ & - & $\mathrm{SOD}$ & $-0,471$ & $0,006^{* *}$ & 33 & $\mathrm{M}$ \\
\hline $\mathrm{Cp}$ & - & $\mathrm{MMA}$ & $0,417^{\dagger}$ & $0,043^{*}$ & 24 & $\mathrm{M}$ \\
\hline $\mathrm{GSH}$ & - & $\mathrm{SOD}$ & $-0,388$ & $0,026^{*}$ & 33 & $\mathrm{~W}$ \\
\hline $\mathrm{MDA}$ & - & $\mathrm{E}$ & 0,489 & $0,005^{\star *}$ & 32 & $\mathrm{M}$ \\
\hline $\mathrm{A}$ & - & $\mathrm{E}$ & 0,567 & $0,001^{* *}$ & 33 & $\mathrm{M}$ \\
\hline
\end{tabular}

\section{Discussion}

The optic neuropathies are various groups of disorders characterized by visual loss resulting from optic nerve dysfunction. According to the World Health Organization, a form of optic neuropathy is responsible for approximately $15 \%$ of the global burden of visual impairment [15]. The importance of oxidative stress in the etiopathogenesis of neurological diseases-like multiple sclerosis; Alzheimer's, Parkinson's [16], and Huntington's diseases [17]; and Graves' ophthalmopathy [18] -is well known. lyer et al. [19] report the role of oxidative stress in the etiopathogenesis of Leber's hereditary optic neuropathy, and antioxidants are recommended for treating this disease. In animal studies, significant differences in MDA, 8-OHdG, GSH, 
and SOD, along with interleukin-1 $\beta$, tumor necrosis factor-alpha, and myeloperoxidase levels were reported in methanol-induced optic neuropathy. They also observe that these changes can be prevented with an effective anti-inflammatory and antioxidant therapy [20]. However, clinical studies on the connection between optic neuropathy and oxidative damage mostly focus on glaucoma, a specific form of optic neuropathy. Oxidative damage plays a key role in the common pathway of various glaucoma types $[2,21]$. It is a valid working hypothesis that a special form of ischemia is the reason for ganglion cell death in glaucoma [21]. On the other hand, the mechanisms responsible for ischemic optic neuropathy include oxidative stress, excitotoxicity, angiogenesis, neuroinflammation, and apoptosis following retinal ischemia [15].

A random-effects meta-analysis of Parkinson's disease, conducted by Wei et al., has shown that patients with Parkinson's have significantly higher levels of blood oxidative stress markers-ferritin, 8-OHdG, nitrite, and MDA-compared with healthy subjects. In contrast, concentrations of UA, catalase, tGSH, and total cholesterol are significantly lower in Parkinson's patients compared with healthy subjects. Interestingly, blood levels of Mn, Cu, Zn, Fe, SOD, albumin, GSH, vitamin E, Cp, triglycerides, LDL-cholesterol, lactoferrin, transferrin, and HDL-cholesterol show no significant differences between Parkinson's patients and healthy subjects. In peripheral blood, significant heterogeneity is reported for 21 of the 22 oxidative stress markers, except for lactoferrin [22]. In comparing the blood biochemistry and oxidative stress parameters between the patient and control groups in the present study, only vitamin E and MDA showed statistically significant increments. This finding is highly concordant with both the meta-analysis of Wei et al. and a similar study carried out by the first author and another research group in 2010. 31 healthy individuals and 160 glaucoma patients were included in the latter multicenter case-control study. SOD and GSH were found to be decreased, and MDA and vitamins A and E were found to be increased, in the patient group. For vitamin E and MDA, this increase was determined to be very significant [23]. Serum MDA levels are increased, not only in the cataract patients [6], but also in primary angle closure glaucoma (PACG) patients [24]. These reports are significant regarding nerve tissue damage, for MDA is an oxidation degradation product and is the most important marker of lipid oxidative damage [1,24]. The increased vitamin E levels reported in patients with optic neuropathy can be explained with the existence of sensitive mechanisms for regulating tissue levels vitamin E. Discovery of membrane receptors and cytosolic transfer proteins specifically tuned to the tocopherol transfer protein, a-tocopherol, strengthens the thesis that vitamin $\mathrm{E}$ derivatives act as neurohormones and initiate various intracellular conduction pathways with a lock-and-key model ${ }^{25}$. In addition to their antioxidative properties, however, molecules of the vitamin E family exert neuroprotective and anti-inflammatory activities $[25,26]$. Due to the antioxidative and neuroprotective potential of vitamin E, protecting lipids from membrane peroxidation, vitamin $E$ supplementation has been suggested as beneficial in many pathologies, including those grounded in neural tissue. Reviewing a large number of meta-analysis, epidemiological, and prospective cohort studies, as well as randomized clinical trials on plasma vitamin E levels and the subsequent risk of developing Alzheimer's disease, Browne et al. [27] concluded that reduced plasma vitamin E status has been associated with increased future risk of developing Alzheimer's, and vitamin E supplementation has been offered for this disease. 
All those articles also imply that the significant and very significant interactions between vitamin $\mathrm{E}, \mathrm{MDA}$ and cholesterol observed in the present study are noteworthy. In a systematic review of 14 observational and seven randomized controlled clinical trials, vitamin E was found to correlate significantly with MDA and SOD [28]. In a clinical study carried out in Africa, patients demonstrated higher plasma atherogenic indices and higher levels of total cholesterol, along with at least 1,334-fold of MDA concentration above normal levels. Also, in the same patients, the higher atherogenic plasmatic index significantly $(p<0.05)$ increased with MDA concentration [29]. Sole supplementation of vitamin E, on the other hand, may act as a stimulant to HMG-CoA activity and, therefore, demonstrate hypercholesterolemic activity [30]. The hypocholesterolemic effects of vitamin $\mathrm{E}$, however, are also well known via several membrane proteins [31] and SREBP/SCAP system [26]. Moreover, significant positive correlation between vitamin E and total cholesterol in lung cancer patients was reported [32].

In correlation analysis between the clinical and bochemical data, significant correlations between color vision and age, as well as between RNFL and vision, are consistent with current clinical knowledge and the extant literature [33]. Prominent results related with vitamins $E$ and $B_{12}$ were observed in the correlation analysis of oxidative stress parameters with clinical and biochemical data, as well as other oxidative stress parameters in the patient group. Vitamin E was found to significantly correlated with IOP in NAION patients. Engin et al. have reported that a-tocopherol exert vasoregulatory effects on the retina, which is important for avoiding ischemia [34]. Another parameter significantly corelated with IOP -UA-is also known to exert protective effects against oxidative damage in the central nervous system. Negative association between UA levels and disease severity has been shown in PACG [35] patients. Significantly higher UA levels, however, have been reported in NTG patients [36].

Along with MDA and cholesterol, Vitamin A was the third molecule to show very significant correlation with vitamin $E$ in this study. Vitamins $A$ and $E$ are fat soluble vitamins absorbed in the small intestine through different, but interrelated, mechanisms. Similar to vitamin E, vitamin A possess antioxidative properties and the ability to regulate gene expression by interacting with the retinoic acid receptors and the retinoid $X$ receptors, acting as transcription factors [37]. An enhanced dietary intake of both vitamin $E$ and $A$ have been reported to be associated with reduced Alzheimer's risk [26]. Furthermore, the antioxidant properties of vitamin $E$ is shown to help to prevent vitamin $A$ oxidation and, therefore, serve to enhance vitamin $A$ absorption when there is concomitant consumption of vitamin $A$ and $E$ [38]. Negative correlation of vitamin A with glucose was found to be weak but significant. It is evident that hepatic glucose and lipid metabolism are regulated by vitamin A metabolites at many different levels [39].

A significant negative correlation between tGSH and SOD have been observed in this study. After screening 12 articles with 646 long-lived participants and 1,052 controls Belenguer-Varea et al. have presented significantly lower SOD and higher glutathione reductase activities in elderly individuals [40], concordant with the present results. Low intake of folate and vitamin $\mathrm{B}_{12}$ has also been found to be associated with reduced levels of tGSH in patients with type 2 diabetes mellitus [41]. In this study, tGSH showed negative and positive significant correlations with both vitamin $\mathrm{B}_{12}$ and MMA, respectively. MMA was also significantly correlated with $\mathrm{Cp}$. $\mathrm{Cp}$ is the carrier of the $\mathrm{Cu}^{++}$ion, which is a cofactor of oxidation 
enzymes, and its deficiency affects optic nerve function, and the nervous system in general [42]. Vitamin $B_{12}$ is another antioxidant whose deficiency causes antioxidant response disorders related to the glutathione system. However, vitamin $\mathrm{B}_{12}$ deficiency can be difficult to diagnose. Due to the lack of a clear association between serum vitamin $\mathrm{B}_{12}$ and its deficiency, it has been proposed that functional vitamin $\mathrm{B}_{12}$ deficiency can occur at any serum level. Morover, it was stated that normal or high serum vitamin $B_{12}$ levels can sometimes be seen in a vitamin $B_{12}$ deficient state [43]. Vitamin $B_{12}$ is required for MMA to be converted to succinyl-CoA. Therefore, a deficiency of vitamin $B_{12}$ at the tissue level can lead to elevation of MMA [8]. In certain circumstances, however, serum vitamin $B_{12}$ and MMA levels may not be correlated, and high levels of MMA has been identified as a better indicator of $B_{12}$ deficiency than the actual serum $B_{12}$ level itself [43]. On the other hand, vitamin $B_{12}$ deficiency is reported to be related to both symptomatic and asymptomatic small fiber loss and retinal nerve fiber thickness in glaucomatous other non-glaucomatous optic neuropathies [44], which highlights the very significant negative correlation of vitamin $B_{12}$ with the $c / d$ ratio. In this study, MD showed significant negative correlations with both MMA and $\mathrm{Cp}$. It has been reported on the association of copper deficiency with the development of concomitant neurologic deficits manifested as peripheral neuropathies and myeloneuropathy indistinguishable from the clinical and T2-weighted MRI findings seen in vitamin B12 deficiency [45].

MDA is an important end product for lipid peroxidation and 8-OHdG is a critical marker for DNA damage, and increases in both MDA an 8-OHdG, implying oxidative damage in lipid tissue, have been reported in PACG [24] patients. Although MDA and 8-OHdG are products of lipid oxidation, damage can occur at various organelles and levels, depending on the composition of the tissue or organ from which the oxidation originates. On the other hand, these two compounds are elements of a complex mechanism and interact with each other. MDA is a known mutagenic and carcinogenic [46] and reacts physiologically with forming deoxyguanosines, including 8-OHdG [3]. Despite MDA being significantly increased among the NAION patients in the present study, neither increase nor correlations of 8-OHdG were statistically significant, -except for a negative correlation with glucose. Although $8-\mathrm{OHdG}$ are identified as important biomarkers in the pathogenesis process of type 2 diabetes mellitus, understandably enhances in blood level as the disease progress [47]. Because reviewing clinical studies on 8-OHdG currently generates interest concerning whether it is an actual marker of DNA damage in lipid tissue due to oxidative stress, variable reports are encountered. 8-OHdG has been reported to be increased in the plasma of Leber's hereditary optic neuropathy [48] and in both the aqueous humor and plasma of POAG patients [49]. Yuki et al., however, studied urine samples in NTG cases and reported decreased urine 8-OHdG/creatinine ratio, which is concordant with the present research [5].

In a recent study among 18 newly diagnosed NAION patients and 17 healthy subjects, along with serum total oxidant and antioxidant status, solely advanced oxidation protein products were studied, and no significant differences were reported between the patients and the control group [50]. The present study is much more comprehensive, with a larger NAION series. Furthermore, the researchers have specifically focused on the products and defense dynamics of lipid oxidation using more sophisticated assay techniques. This study not only obtained clear information regarding oxidative damage and antioxidant 
response in a frequent form of optic neuropathy, but it also pointed out specific interactions between neuromodulators, like vitamin $\mathrm{E}$, and intracellular signaling and regulation mechanisms. Better reading of these connections and focusing on oxidative nerve tissue damage may aid the development of more suitable diagnosis, follow-up and treatment criteria and strategies, alongside a fuller understanding of NAION.

\section{Declarations}

*The authors report no conflicts of interest. The study was sponsoured by BAP- İzmir Dokuz Eylül University Research Fund (2016.KB.SAG.062).

*None of the authors had any financial support or relationships that may pose conflict of interest.

\section{References}

1. Bernstein SL, Johnson MA, Miller NR (2011) Nonarteritic anterior ischemic optic neuropathy (NAION) and its experimental models. Prog Retin Eye Res 30(3):167-187

2. Tezel G (2006) Oxidative Stress in Glaucomatous Neurodegeneration: Mechanisms and Consequences. Prog Retin Eye Res 5(5):490-513

3. Antonio A, Muñoz MF, Argüelles S (2014) Lipid peroxidation: production, metabolism, and signaling mechanisms of malondialdehyde and 4-hydroxy-2-nonenal. Oxid med cell longev 2014:360438

4. Marrocco I, Altieri P, Peluso I (2017) Measurement and Clinical Significance of Biomarkers of Oxidative Stress in Humans. Oxid Med Cell Longev 2017:6501046

5. Yuki K, Murat D, Kimura I, Tsubota K (2010) Increased serum total antioxidant status and decreased urinary 8-hydroxy-2'-deoxyguanosine levels in patients with normal-tension glaucoma. Acta Ophthalmol 88(7):e259-264

6. Yilmaz A, Adigüzel U, Tamer L, Yildirim O, Oz O, Vatansever $\mathrm{H}$ et al (2005) Serum oxidant/antioxidant balance in exfoliation syndrome. Clin Experiment Ophthalmol 33(1):63-66

7. Tousignant B, Brian G, Venn BJ, Gould C, McKay R, Williams S (2013) Optic neuropathy among a prison population in Papua New Guinea. Ophthalmic Epidemiol 20(1):4-12

8. Bitik B, Tufan A, Elbeg Ş, Mercan R, Küçük H, Küçükşahin O et al (2017) Serum Vitamin B12, Homocysteine and Methylmalonic Acid Levels in Patients with Parenchymal Neuro-Behçet's Syndrome. Arch Rheumatol 32(2):118-122

9. Hong YL, Yeh SL, Chang CY, Hu ML (2000) Total plasma malondialdehyde levels in 16 Taiwanese college students determined by various thiobarbituric acid tests and an improved high-performance liquid chromatography-based method. Clin Biochem 33(8):619-625

10. Senft AP, Dalton TP, Shertzer HG (2000) Determining glutathione and glutathione disulfide using the fluorescence probe o-phthalaldehyde. Anal Biochem 280(1):80-86 
11. Akış M, Kant M, Işık I, Kısa-Teke P, Köse $E$, Arslan N et al (2020) Functional vitamin B12 defıciency in phenylketonuria patients and healthy controls: An evaluation with combined indicator of vitamin B12 status as a biochemical index. Ann Clinical Biochem 57(4):291-299

12. Aparicio-Ugarriza R, Palacios G, Alder M, Gonzales-Gross M (2015) A review of the cut-off points for the diagnosis of vitamin B12 deficiency in the general population. Clin Chem Lab Med 53:11491159

13. Jaruga P, Dizdaroglu M (2010) Identification and quantification of (5'R)- and (5'S)-8,5'-cyclo-2'deoxyadenosines in human urine as putative biomarkers of oxidatively induced damage to DNA. Biochem Biophys Res Commun 397(1):48-52

14. Kant M, Akıs M, Calan M, Arkan T, Bayraktar F, Dizdaroglu M et al (2016) Elevated Urinary Levels of 8hydroxy-2'-deoxyguanosine, (5'R)- and (5'S)-8,5'-cyclo-2'-deoxyadenosines, and 8-iso-prostaglandin F2a as Potential Biomarkers of Oxidative Stress in Patients with Prediabetes. DNA Repair 48:1-7

15. Khalilpour S, Shahrzad L, Behnammanesh G, Abdul Majid AMS, Abdul Majid AS, Tamayol A (2017) Ischemic optic neuropathy as a model of neurodegenerative disorder: A review of pathogenic mechanism of axonal degeneration and the role of neuroprotection. J Neurologic Sci 375:430-441

16. Yan MH, Wang X, Zhu X (2013) Mitochondrial defects and oxidative stress in Alzheimer disease and Parkinson disease. Free Radic Biol Med 62:90-101

17. Chang KH, Cheng ML, Chiang MC, Chen CM (2018) Lipophilic antioxidants in neurodegenerative diseases. Clin Chim Acta 485:79-87

18. Bartalena L, Tanda ML, Piantanida E, Lai A (2003) Oxidative stress and Graves' ophthalmopathy: in vitro studies and therapeutic implications. BioFactors 19(3-4):155-163

19. Iyer S (2013) Novel therapeutic approaches for Leber's hereditary optic neuropathy. Discov Med 15(82):141-149

20. Taşlı NG, Çimen FK, Karakurt Y, Uçak T, Mammadov R, Süleyman B et al (2018) Protective effects of Rutin against methanol induced acute toxic optic neuropathy: an experimental study. Int J Ophthalmol 11(5):780-785

21. Gupta N, Yücel YH (2007) Glaucoma as a neurodegenerative disease. Curr Opin Ophthalmol 18:110114

22. Wei Z, Li X, Li X, Liu Q, Cheng Y (2018) Oxidative Stress in Parkinson's Disease: A Systematic Review and Meta-Analysis. Front Mol Neurosci 11:236

23. Engin KN, Yemişci B, Yiğit U, Ağaçhan A, Coşkun C (2010) Variability of serum oxidative stress indicators according to biochemical datae and clinical parameters of glaucoma. Mol Vis 16:12601271

24. Chang D, Sha Q, Zhang X, Liu P, Rong S, Han T et al (2011) The evaluation of the oxidative stress parameters in patients with primary angle-closure glaucoma. PLoS ONE 6(11):e27218

25. Engin KN (2009) Alpha Tocopherol: Looking beyond an antioxidant. Mol Vis 15:855-860 
26. Grimm MO, Mett J, Hartmann T (2016) The Impact of Vitamin E and Other Fat-Soluble Vitamins on Alzheimer's Disease. Int J Mol Sci 17(11):E1785

27. Browne D, McGuinness B, Woodside JV, McKay GJ (2019) Vitamin E and Alzheimer's disease: what do we know so far? Clin Interv Aging 14:1303-1307

28. Tabatabaei-Malazy O, Ardeshirlarijani E, Namazi N, Nikfar S, Larijani B (2019) Dietary antioxidative supplements and diabetic retinopathy; a systematic review. J Diabetes Metab Disord 18(2):705-716

29. Kubong LN, Nya Biapa PC, Chetcha B, Yanou-Njintang N, Moor Ama VJ, Pieme CA (2020) Relationship between Higher Atherogenic Index of Plasma and Oxidative Stress of a Group of Patients Living with Sickle Cell Anemia in Cameroon. Adv Hematol 2020:9864371

30. Khor HT, Ng TT (2000) Effects of administration of alpha-tocopherol and tocotrienols on serum lipids and liver HMG CoA reductase activity. Int J Food Sci Nutr 51(Suppl):S3-S11

31. Yamanashi Y, Takada T, Kurauchi R, Tanaka Y, Komine T, Suzuki H (2017) Transporters for the Intestinal Absorption of Cholesterol, Vitamin E, and Vitamin K. J Atheroscler Thromb 24(4):347-359

32. Zabłocka-Słowińska K, Płaczkowska S, Skórska K, Prescha A, Pawełczyk K, Porębska I et al (2019) Oxidative stress in lung cancer patients is associated with altered serum markers of lipid metabolism. PLoS ONE 14(4):e0215246

33. Fitzgerald MJT, Folan-Curran J (2002) Central Visual Pathways.. In: In: Fitzgerald MJT, Folan-Curran $\mathrm{J}$ (eds) Clinical Neuroanatomy and Related Neuroscience. W.B.Saunders, Spain, pp 231-240

34. Engin KN, Engin G, Kücükşahin H, Oncu M, Engin G, Guvener B (2007) Clinical evaluation of the neuroprotective effect of a-tocopherol on retına against glaucomatous damage. Eur $\mathrm{J}$ Ophthalmol 17(4):528-533

35. Li S, Shao M, Tang B, Zhang A, Cao W, Sun X (2017) The association between serum uric acid and glaucoma severity in primary angle closure glaucoma: a retrospective case-control study. Oncotarget 8(2):2816-2824

36. Yuki K, Murat D, Kimura I, Ohtake Y, Tsubota K (2010) Reduced-serum vitamin C and increased uric acid levels in normal-tension glaucoma. Graefes Arch Clin Exp Ophthalmol 248(2):243-248

37. Goncalves A, Roi S, Nowicki M, Dhaussy A, Huertas A, Amiot MJ et al (2015) Fat-soluble vitamin intestinal absorption: absorption sites in the intestine and interactions for absorption. Food Chem 172:155-160

38. Albahrani AA, Greaves RF (2016) Fat-Soluble Vitamins: Clinical Indications and Current Challenges for Chromatographic Measurement. Clin Biochem Rev 37(1):27-47

39. Trasino SE, Tang XH, Jessurun J, Gudas LJ (2016) Retinoic acid receptor $\beta 2$ agonists restore glycaemic control in diabetes and reduce steatosis. Diabetes Obes Metab 18(2):142-151

40. Belenguer-Varea Á, Tarazona-Santabalbina FJ, Avellana-Zaragoza JA, Martínez-Reig M, Mas-Bargues C, Inglés M (2020) Oxidative stress and exceptional human longevity: Systematic review. Free Radic Biol Med 149:51-63 
41. Al-Maskari MY, Waly MI, Ali A, Al-Shuaibi YS, Ouhtit A (2012) Folate and vitamin B12 deficiency and hyperhomocysteinemia promote oxidative stress in adult type 2 diabetes. Nutrition 28(7-8):e23-e26

42. Wang B, Wang XP (2019) Does Ceruloplasmin Defend Against Neurodegenerative Diseases? Curr Neuropharmacol 17(6):539-549

43. Vashi P, Edwin P, Popiel B, Lammersfeld CD (2016) Methylmalonic Acid and Homocysteine as Indicators of Vitamin B-12 Deficiency in Cancer. PLoS ONE 11(1):e0147843

44. Türkyılmaz K, Öner V, Türkyılmaz AK, Kırbaş A, Kırbaş S, Şekeryapan B (2013) Evaluation of peripapillary retinal nerve fiber layer thickness in patients with vitamin B12 deficiency using spectral domain optical coherence tomography. Curr Eye Res 38(6):680-684

45. Kimura E, Hirano T, Yamashita S, Hirai T, Uchida Y, Maeda Y, Uchino M (2011) Cervical MRI of subacute myelo-optico-neuropathy. Spinal Cord 49(2):182-185

46. Marnett LJ (1999) Lipid peroxidation-DNA damage by malondialdehyde. Mutat Res 424(1-2):83-95

47. Huang TF, Tang ZP, Wang S, Hu MW, Zhan L, Yi Y et al (2019) Decrease in Serum Levels of Adiponectin and Increase in 8-OHdG: a Culprit for Cognitive Impairment in the Elderly Patients with Type 2 Diabetes. Curr Mol Med 20(1):44-50

48. Yen MY, Kao SH, Wang AG, Wei YH (2004) Increased 8-hydroxy-2'-deoxyguanosine in leukocyte DNA in Leber's hereditary optic neuropathy. Invest Ophthalmol Vis Sci 45(6):1688-1691

49. Mohanty K, Dada R, Dada T (2017) Oxidative DNA damage and reduced expression of DNA repair genes: Role in primary open angle glaucoma (POAG). Ophthalmic Genet 38(5):446-450

50. Birer S, Arda H, Kilic D, Baskol G (2019) Systemic oxidative stress in non-arteritic anterior ischemic optic neuropathy. Eye 33(7):1140-1144

\section{Figures}




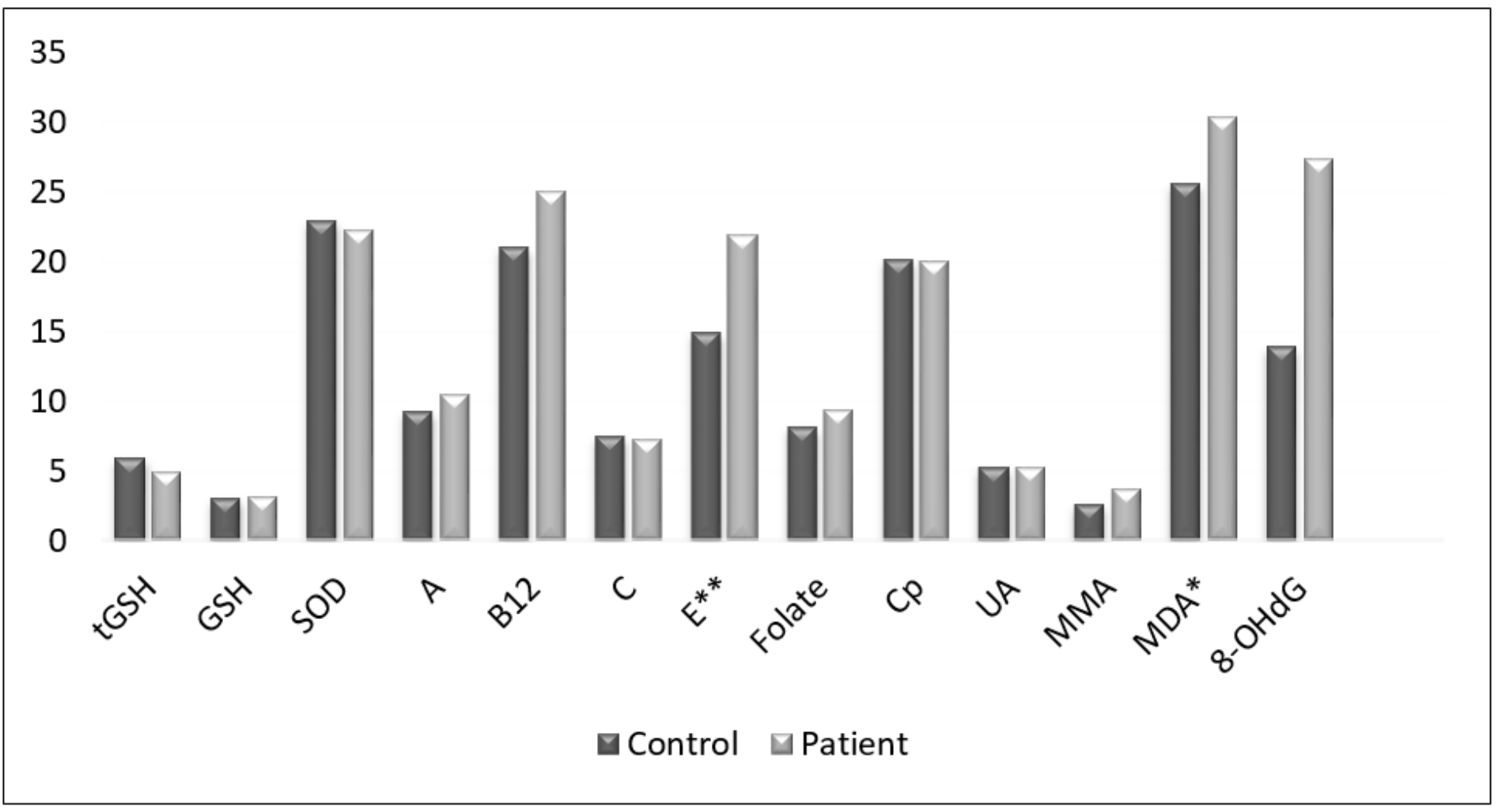

\section{Figure 1}

Comparison of blood biochemistry and oxidative stress parameters between patient and control groups. tGSH: Total glutathione (mmol/L x100), GSH: Reduced glutathione, (mmol/L x100), SOD: Superoxide dismutase $(\mu \mathrm{mol} / \mathrm{mg}), A:$ Vitamin A ( $\mu \mathrm{g} / \mathrm{L} / 100), B 12$ : Vitamin B12 $(\mathrm{pg} / \mathrm{mL} / 10)$, C: Vitamin C $(\mathrm{ng} / \mu \mathrm{L}$ $x 100)$, E: Vitamin $E(\mu \mathrm{g} / \mathrm{L})$, Folate $(\mathrm{ng} / \mathrm{mL}), \mathrm{Cp}$ : Ceruloplasmin (mg/dL), UA: Uric acid, $(\mu \mathrm{g} / \mathrm{L}), \mathrm{MMA}$ : Methylmalonic acid ( $\mu \mathrm{mol} / \mathrm{L}$ x10), MDA: Malonyl dialdehyde ( $\mu \mathrm{mol} / \mathrm{L}$ x10), 8-OHdG: 8-hydroxy-2'deoxyguanosine/Creatinine $(\mathrm{nmol} / \mathrm{mmol}), *: p<0.05$ significant, $* *: p<0.001$ very significant.

\section{Supplementary Files}

This is a list of supplementary files associated with this preprint. Click to download.

- ESM1.docx

- ESM2.docx

- ESM3.docx

- ESM4.docx

- ESM5.docx

- ESM6.docx

- ESM7.docx 